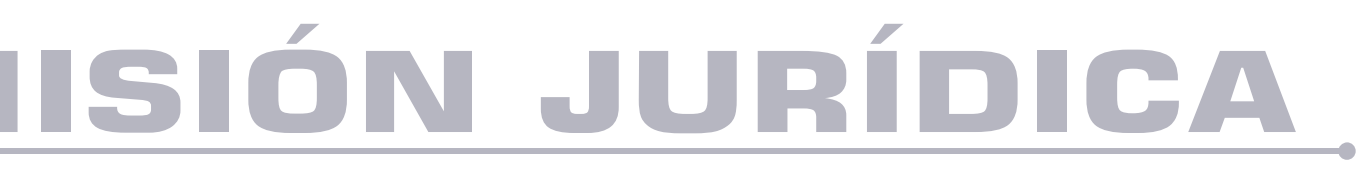

\title{
El deber de información en un contrato de cesión de contrato
}

Disclosure of information in an assignment contract

Autor: Paula Andrea Abondano Almeida

DOl: https://doi.org/10.25058/1794600X.1920

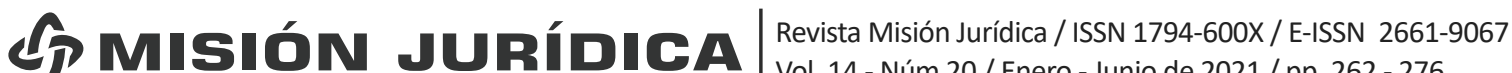




\title{
EL DEBER DE INFORMACIÓN EN UN CONTRATO DE CESIÓN DE CONTRATO *
}

\author{
Disclosure of information in an assignment contract
}

O dever de informação em um contrato de cessão de contrato

Paula Andrea Abondano Almeida ${ }^{a}$ paula.abondano@hotmail.com

Fecha de recepción: 2 de diciembre de 2020 Fecha de revisión: 12 de diciembre de 2020

Fecha de aceptación: 22 de enero de 2021

\section{RESUMEN}

El deber de información es derivado del principio de la buena fe, aplicable en los contratos y exigible para el contratante poseedor de la información y para el que la desconoce, quien debe evitar estado de ignorancia. Este artículo pretende responder porqué, en un evento de responsabilidad en una cesión de contrato, merece mayor reproche la conducta del cesionario negligente, quien no solicita la información pertinente respecto del contrato cedido, frente a su co-contratante poseedor de dicha información, y que no la entrega intencionalmente. Para determinar el alcance del deber de información a cargo de los contratantes, se hace una revisión de normas jurídicas, doctrina, jurisprudencia y el estudio de los deberes de información, diligencia, lealtad, prohibición de ir en

\footnotetext{
* Artículo resultado de la línea de investigación llevada a cabo en el seno de la Facultad de Jurisprudencia del Colegio Mayor de Nuestra Señora del Rosario -Maestría en Derecho con énfasis en Derecho Privado, periodo 2017 -2019. Tutor Dr. Francisco José Ternera Barrios, Magistrado Corte Suprema de Justicia. Año 2020. Bogotá D.C., Colombia.

a. Especialista en Derecho contractual y relaciones jurídico negociales de la Universidad Externado de Colombia y abogada egresada de la misma Universidad.
} 
contra de los actos propios, concluyendo que la negligencia y la violación del deber de autoinformación no merecen protección jurídica.

\section{PALABRAS CLAVE}

Buena fe contractual; buena fe objetiva; cesión de contrato; deber de información de los contratantes; diligencia; lealtad contractual.

\section{ABSTRACT}

Disclosure of information is derived from the principle of good faith which is applicable to contracts. It is enforceable both against the contracting party who possesses the information and to the one who ignores it but has a duty to avoid a state of ignorance. This article aims to answer why, in the event of liability in the assignment contract; there is more reproach to be appointed to the behavior of the negligent transferee who does not request the pertinent information regarding the ceded contract than to the counterparty who intentionally withholds such information. To determine the scope of the duty to disclose information for each party, a revision of the legal framework was pursued including regulations, doctrine, jurisprudence as well as the study of the duties of information, diligence, loyalty and the non venire contram factum proprium prohibition. It was concluded that negligence and the breach of the duty of selfinformation do not deserve legal protection.

\section{KEY WORDS}

Assignment contract; good faith; good faith in contract law; diligence; loyalty; disclosure of information.

\section{RESUMO}

0 dever de informação decorre do princípio da boa fé, aplicável em contrato e exequível para o contratante que possui a informação e para quem não a conhece, que deve evitar o estado de ignorância. Este artigo visa responder por que, em caso de responsabilidade em uma cessão de contrato, a conduta negligente do cessionário, que não solicita as informações pertinentes a respeito do contrato cedido, merece maior censura, e que não o entrega intencionalmente. Para determinar o âmbito do dever de informação a cargo das partes contratantes, procede-se à revisão das normas legais, doutrinárias, jurisprudenciais e ao estudo dos deveres de informação, diligência, lealdade, proibição de ir contra os próprios atos, concluindo que a negligência e a violação do dever de autoinformação não merecem proteção legal.

\section{PALAVRAS-CHAVE}

Boa-fé contratual; boa-fé objetiva; cessão de contrato; dever de informação das partes contratantes; diligência; lealdade contratual.

\section{INTRODUCCIÓN}

La cesión de contrato, negocio jurídico bilateral regulado por el derecho mercantil en Colombia, dista de la cesión de crédito, principalmente porque "cuando se cede un crédito se transmite el derecho. [...] el cesionario recibe un derecho a cargo del tercero deudor, pero no se obliga para con este" (Hinestrosa, 2003, p. 525), mientras que en la cesión de un contrato

El objeto de la operación es el traspaso simultáneo de unos créditos y de las obligaciones recíprocas, surgidos a una de un mismo contrato, por parte de uno de los contratantes a un tercero, esto es, en últimas, la transferencia de una posición o relación contractual, cuyo resultado es la sustitución de una de las partes (acreedora-deudora) (p. 526).

Así, por ejemplo, en un contrato mercantil de tracto sucesivo en que las circunstancias cambien para una de las partes, pero se desee continuar con el contrato, la parte afectada puede ceder el contrato a un tercero, mediante el contrato de cesión. Para Mantilla et al. (2007), esta figura es una alternativa para preservar la convención en el evento en que una de las partes desee sustraerse de la relación contractual, pues permite la continuación de la operación económica aun cuando una de las partes no puede o no está interesada en continuarla por sí misma.

Este contrato se encuentra tipificado en Colombia en los artículos 887 a 896 del Código de Comercio, en los que se prevé, entre otras cosas, que:

En los contratos de ejecución sucesiva cada una de las partes podrá hacerse sustituir por un tercero, en la totalidad o en parte 
de las relaciones derivadas del contrato, sin necesidad de aceptación expresa del contratante cedido. Adicionalmente se podrá pactar que si el contratante cedido hace la reserva de no liberar al cedente [...] podrá exigir del cedente el cumplimiento de las obligaciones derivadas del contrato cuando el cesionario no las cumpla (1971).

En principio este contrato no genera mayores discusiones. Sin embargo, aún no es claro de quién es la responsabilidad, en el evento en que un cedente se encuentre previamente en incumplimiento del contrato objeto de cesión y, decida ceder el negocio jurídico, omitiendo información a un tercero cesionario quien actúa pasiva y negligentemente, y tampoco exige esa información.

Respecto a la responsabilidad derivada del incumplimiento no informado del cedente y para determinar quién debe asumir dicha carga, se ha de analizar el caso propuesto en este artículo a la luz del Código de Comercio y en especial del principio de buena fe, que irriga a todo el ordenamiento jurídico y que es de obligatoria aplicación en todas las etapas del contrato precontractual, ejecución del contrato y pos contractual-, pues de esta manera lo disponen los artículos 83 de la Constitución Política de Colombia, 1603 del Código Civil y 863 del Código de Comercio.

Fernando Hinestrosa (2000) ha señalado que:

La buena fe como principio cumbre del derecho se vierte en la disciplina del contrato a partir de negociaciones, sigue el proceso de la oferta y la celebración del contrato, está presente en el transcurso de la ejecución de las prestaciones y va, inclusive, hasta después de la terminación del contrato (p. 21).

A partir de esta situación se busca determinar cuál es la conducta que merece mayor reproche, si la del cedente reticente a la entrega de información relevante del contrato cedido, o la del cesionario negligente en la exigencia de dicha información. Así, se plantean como objetivos: 1) estudiar las características de un contrato de sesión; 2) analizar el marco conceptual y doctrinal de principio de buena fe en el contexto de un contrato de cesión; y 3) analizar y determinar el alcance del deber de información en cabeza del cedente y del deber de corrección cesionario en un evento de responsabilidad.

\section{METODOLOGÍA}

En este estudio se hace inicialmente una breve referencia al contrato de cesión y se analiza el marco conceptual y doctrinal del principio de buena fe subjetiva y objetiva, en el contexto del contrato de cesión, para luego precisar el alcance del deber de información a cargo del cedente y especialmente del deber de corrección o correlativo de auto-información del cesionario, y la regla de la prohibición de ir en contra de los actos propios.

Con el propósito de iniciar el análisis referido, se toma como guía el siguiente caso: "A" y "B" celebran un contrato de distribución de combustible por el término de 10 años, en el que " $A$ " se encarga de entregar el combustible a " $\mathrm{B}$ " $\mathrm{y}$ " $\mathrm{B}$ " se obliga a pagar el precio convenido y a vender una cantidad mínima del combustible en una estación de servicio de su propiedad. Durante la vigencia del contrato, "B" atraviesa una crisis económica que le impide continuar con la ejecución del mismo, por lo que decide cerrar sus operaciones y cede su contrato a "C", quien acepta de forma inmediata el contrato cedido sin estudiarlo, ni requerir más información que la suministrada por "B". "C" es un reconocido $\mathrm{y}$ experimentado comerciante que se dedica habitualmente a la inversión de capital en negocios que considera lucrativos. En la cesión del contrato, no se pactan cláusulas de responsabilidad, ni se hacen reservas de ningún tipo. Después de la cesión, "A" pretende demandar a " $C$ " por el incumplimiento presentado de las obligaciones del contrato de distribución desde antes de la cesión, situación no informada por "B". Con base en ello "C" alega que "B" actuó de mala fe por no haberle informado sobre tales incumplimientos, por su parte "B" alega que "C" actuó negligentemente al haber aceptado la cesión del contrato sin cuestionamientos.

\section{Resultados y discusión}

\section{Contrato de cesión de contrato en Colombia - aspectos generales-}

La cesión de contrato puede clasificarse como un contrato mercantil, principal, típico, bilateral, oneroso, conmutativo y consensual, que prevé la posibilidad de que una de las partes de otro contrato previamente celebrado pueda cederlo 
-ceder su posición contractual- a un tercero, total o parcialmente.

A diferencia de la cesión de crédito, en el que el cedente transfiere el derecho a un tercero, en la cesión de un contrato el cesionario adquiere las pretensiones crediticias, a la vez que asume las obligaciones del cedente y éste sale de la relación y queda liberado de obligaciones y responsabilidad para con el contratante cedido (Hinestrosa, 2002, p. 526).

La regulación de este contrato se encuentra en los artículos 887 a 896 del Código de Comercio en Colombia, figura que resulta de gran utilidad en el tráfico mercantil, como quiera que los contratantes, todos o cualquiera de ellos, puedan hacerse sustituir por un tercero en cualquier momento del iter contractual. La cesión hace posible la circulación del interés económico trabado en el contrato. La circunstancia de que una de las partes intervinientes en el contrato pueda hacerse reemplazar por un tercero extraño en la formación del mismo, permite el tráfico aludido, según Arrubla (2008).

Para que la cesión sea válida, conforme a las disposiciones del Código de Comercio es indispensable que se observen los siguientes requisitos:

a. El contrato que se pretenda ceder debe estar vigente y debe ser de ejecución sucesiva o de ejecución instantánea. En este último caso siempre que no haya sido cumplido en todo o en parte.

b. No haya prohibición o limitación legal o contractual respecto de la cesión.

c. En los casos de contratos intuito persona, se requiere la aceptación expresa del contratante cedido.

d. Se debe realizar verbalmente o por escrito, según el contrato que se vaya a ceder.

e. Se deben observar las disposiciones contractuales que las partes hayan pactado al respecto.

Para Díez y Guillón (1987) esta figura puede resultar más compleja, pues se transfiriere en bloque la totalidad de los efectos, es decir se trata de la transmisión de una posición jurídica compleja, y por ende, la cesión tiene un pleno alcance objetivo, es decir, no afecta solo a los derechos y a las obligaciones, sino a los efectos contractuales que tuviera lugar (por ejemplo, las excepciones, las condiciones, etc.), y asimismo, la producción de sus consecuencias se realiza con recíproca interdependencia en todas sus partes.

\section{Partes en el Contrato de cesión}

En palabras de Luis Muñoz (1960), la parte contractual que cede el contrato se debe llamar cedente, y el extraño que sub-entra como parte en el negocio bilateral cesionario, ya que el cedente transfiere su calidad de parte al tercero, y también su calidad de contraparte respecto del cedido, que es la parte que no hizo cesión de su calidad de tal $\mathrm{y}$, por consiguiente sigue siendo parte originaria del contrato.

Teniendo en cuenta el ejemplo dado en la introducción, por un lado, las partes del contrato de distribución serían "A" empresario y "B" distribuidor. Por otro lado, en el contrato de cesión las partes corresponderían a "B" contratante cedente y " $C$ " cesionario. De esta manera " $B$ " tendrá una doble característica como distribuidor y cedente.

\section{La calidad jurídica del contratante cedido}

A pesar que en el ejemplo, "A" sea el contratante cedido, no hace parte del contrato de cesión, pues su aprobación o desaprobación de la cesión no tiene injerencia alguna -inicialmenteen la celebración del contrato entre "B" y "C".

Adicionalmente, del contrato de cesión no nacen obligaciones a cargo de "A", ya que el contrato de distribución continúa vigente, no se han modificado sus deberes y la cesión de este contrato no acarrea nuevas obligaciones para el contratante cedido. Así "A" jurídicamente no hace parte del contrato de cesión. Es claro el artículo 894 del Código de Comercio cuando indica que la cesión de un contrato produce efectos entre cedente y cesionario desde que aquella se celebre, pero respecto del contratante cedido y de terceros, solo produce efectos desde la notificación o aceptación.

Sin embargo, el artículo 893 del Código de Comercio señala que en los eventos en que se requiera la aceptación o notificación al contratante cedido de la cesión del contrato para liberar, o no 
al cedente y, el contratante cedido no la hubiera aprobado previamente, este podrá exigir del cedente el cumplimiento de las obligaciones derivadas del contrato cuando el cesionario no las cumpla, pero deberá informar del incumplimiento al cedente dentro de los diez días siguientes a la mora del deudor (Código de Comercio, 1971)

Así mismo, el artículo 896 del Código de Comercio establece que:

El contratante cedido podrá oponer al cesionario todas las excepciones que se deriven del contrato. Podrá también oponer aquellas que se funden sobre otras relaciones con el cedente, respecto de las cuales haya hecho expresa reserva al momento de notificársele o aceptar la cesión.

Así que, si inicialmente no se considera al contratante cedido como una parte dentro del contrato de cesión, lo cierto es que este puede participar en dicho contrato a través de las conductas que la ley le permite con el fin de menguar los efectos de la cesión, permitiéndole oponer todas las excepciones derivadas del contrato.

Por otra parte, frente a la validez del contrato en comento y la aceptación por parte del contratante cedido, la Corte Suprema de Justicia ha señalado que:

Puede predicarse con independencia de la aceptación expresa del contratante cedido, salvo que exista prohibición legal o las partes hayan limitado o proscrito la sustitución. Por supuesto, que una cosa es la aceptación como condición de validez, que no se precisa, y otra el rol que ella juega para determinar los efectos de la cesión, pues mientras que estos se producen entre el cedente y el cesionario, desde cuando el acto se celebra, tratándose del contratante cedido y de terceros, estos sólo se producen "desde la notificación o aceptación, salvo lo previsto en el inciso tercero del artículo 888 (Sala de Casación Civil, SS063-5628, 2001).

Es decir que la aceptación por parte del contratante cedido no es un requisito en el régimen general de la cesión de contrato, pero si se requiere, a lo menos, la notificación de la cesión a aquel.

\section{Obligaciones de las partes}

Según los artículos ya referidos las obligaciones de "B" como contratante cedente recaen en que debe responder por la existencia y validez del contrato cedido y sus garantías, y en caso de pactarse, responder por el cumplimiento del contrato. Por su parte, las obligaciones de "C" como cesionario consisten en que deberá dar aviso al cedente dentro de los diez días siguientes al incumplimiento, si se pacta que el cedente responderá por el cumplimiento del contrato cedido.

Además de las obligaciones legales, las partes pueden acordar otras obligaciones o condiciones contractualmente, tales como el grado de responsabilidad de cada una, también podrían guardar silencio y aceptar tácitamente las reglas establecidas en la ley, como se indicó en el ejemplo inicial.

No obstante, estas no son las únicas obligaciones del cedente y cesionario, pues los contratantes están obligados a cumplir adicionalmente con aquello que voluntariamente se pacte en el contrato, así como lo que se encuentre de manera general en el ordenamiento jurídico y les sea aplicable y en especial el principio de la buena fe.

Así lo dispone el artículo 871 del Código de Comercio: "Principio de buena fe. Los contratos deberán celebrarse y ejecutarse de buena fe $y$, en consecuencia, obligarán no sólo a lo pactado expresamente en ellos, sino a todo lo que corresponda a la naturaleza de estos, según la ley, la costumbre o la equidad natural".

\section{Alcance del contrato de cesión respecto del contrato principal}

"La cesión de un contrato produce efectos entre cedente y cesionario desde que aquella se celebre; pero respecto del contratante cedido y de terceros, sólo produce efectos desde la notificación o aceptación" (Código de Comercio, 1971, p. 170)

Para Muñoz (1960) los efectos de la cesión del contrato deben examinarse en relación con el cedente, el cesionario y el cedido, lo que exige tener en cuenta las diversas relaciones entre ellos. a) El cedente. - Si la cesión del contrato resulta eficaz porque el cedido, que es la contraparte del cedente, presta su asentimiento a la cesión, 
el cedente se libera de sus obligaciones, y, naturalmente, pierde también frente al cedido sus derechos que traen causa del contrato. [...] b) El cedido y el cesionario. - El cedido es la contraparte del cedente, y el cesionario la persona extraña que sub-entra en el contrato que se cede. Pues bien, el contratante cedido y el cesionario llegan a ser, recíprocamente, y en virtud de la cesión del contrato, partes de este. En consecuencia, el cedido deberá poder oponer al cesionario (tercero) las excepciones derivadas del contrato, pero no las que se funden en las relaciones propias con el cedente y que no dependan del contrato objeto de la cesión, a no ser que el cedido haya hecho expresa reserva en el momento en que asintió en la cesión.

Ahora bien, si conforme al artículo 893 del Código de Comercio el contratante cedido hace la reserva de no liberar al cedente, podrá exigir del cedente el cumplimiento de las obligaciones derivadas del contrato cuando el cesionario no las cumpla, pero deberá poner el incumplimiento en conocimiento del cedente dentro de los diez días siguientes a la mora del deudor (Hinestrosa, 2002, p. 537).

En el ejemplo propuesto, además de que las partes no hicieron ninguna reserva sobre la cesión, el contrato de distribución no sufre ninguna modificación y los derechos y obligaciones permanecen intactos, por lo que el cesionario " $\mathrm{C}$ " recibe el contrato principal en el estado en que se viene ejecutando; es decir, en estado de incumplimiento frente a " $\mathrm{A}$ ", de tal forma que el contrato de distribución se recibe en el estado en que se encuentre.

\section{Principio de la buena fe contractual}

La buena fe como principio rector del ordenamiento jurídico, guía la conducta de quienes intervienen en el contrato, en cualquiera de sus etapas, pues es de cumplimiento obligatorio; bien sea que se traduzca en los deberes impuestos expresamente en las normas expedidas o bien en aquellas reglas propias de este principio. De ahí que, Neme Villareal (2010) expresa que en aras de establecer el alcance del deber de actuar de buena fe, resulte indispensable examinar las reglas que de dicho principio se derivan.

De acuerdo a Neme (2009), la buena fe tiene dos acepciones: la buena fe subjetiva y, la buena fe objetiva; entendida la primera, como un estado de conciencia, un convencimiento, la intención del sujeto, su estado psicológico, su íntima convicción; y la buena fe objetiva, que se erige en regla de conducta fundada en la honestidad, en la rectitud, en la lealtad y principalmente en la consideración del interés del otro visto como un miembro del conjunto social que es jurídicamente tutelado. La buena fe objetiva presupone que se actúe con honradez, probidad, honorabilidad, transparencia, diligencia, responsabilidad y sin dobleces, entre otros deberes que emanan permanentemente de su profuso carácter normativo.

Como Neme (2006) expresó, las partes del contrato deben actuar diligentemente, honrando lo pactado, haciendo todo lo posible para que los propósitos del negocio se cumplan de la mejor forma, evitando dilaciones, entregando información que se pueda considerar relevante. Las anteriores son reglas de obligatorio cumplimiento en virtud de la fuerza integradora de la buena fe y de su carácter normativo que se entienden incorporadas al contrato, atendiendo a la naturaleza del mismo y de las particulares circunstancias del caso, sin necesidad de que hayan sido expresamente pactadas por las partes.

Es importante enfatizar en que la diligencia, colaboración, solidaridad, claridad, equilibrio, reciprocidad y lealtad, entre otras, son reglas que se derivan de la buena fe objetiva y que es ésta la que se debe aplicar a las relaciones contractuales, pues como se ve, la buena fe subjetiva en sí misma no implica el despliegue de conductas verificables por parte de los contratantes.

En concreto, el papel principal de la buena fe subjetiva es otorgar un derecho, y el de la buena fe objetiva es imponer deberes. La buena fe objetiva exige una conducta, como vimos, de fidelidad, de honestidad, de cooperación, y se ubica como una norma dispositiva. De aquí, según Ordoqui (2012a), su naturaleza objetiva se funda en la adecuación de esa voluntad al principio de la buena fe que inspira y fundamenta el vínculo negocial ( 2012c)

Neme (2010) manifiesta que no puede, entonces, confundirse la buena fe objetiva, que implica actuar según unas reglas y deberes, con la buena fe subjetiva, pues esta es un estado de conciencia, en el que la parte considera que está actuando conforme las normas dictadas y que no se le obliga a desplegar ninguna conducta en la 
ejecución del contrato, por lo que dicha parte se defiende alegando creer actuar correctamente aun cuando su acción u omisión sean reprochables.

\section{Buena fe objetiva $y$ algunas reglas principales que se derivan de ésta}

Para Ordoqui (2012b), en consideración de que la buena fe subjetiva no es la vinculante para el ordenamiento jurídico, por tratarse de un estado de conciencia de convencimiento de estar actuando conforme a las normas, se debe tener en cuenta, entonces, que es la buena fe objetiva la que ata el comportamiento de los contratantes. Por tanto, desde el punto de vista objetivo, la buena fe aparece como un deber de conducta, donde las reglas derivadas se traducen en deberes que colaboran a flexibilizar la integración e interpretación del contrato al orden jurídico vigente.

La buena fe objetiva es la creadora de la confianza legítima en la contraparte porque los actos desplegados por ese contratante están encaminados a la ejecución del contrato para lograr el objetivo propuesto en este. Entonces, según los expresado por Jaramillo (2017), la buena fe se torna en una herramienta para hacer viable el ejercicio de los derechos, así no aparezcan expresamente tatuados y también para que sirva de dique contenedor de lecturas o visiones restrictivas que, in radice, socaven la confianza legítima suscitada en uno de los co-contratantes, o que estimulen la insolidaridad negocial llamada a desconocer el correlativo interés del otro.

Para Neme (2006) dentro de las reglas derivadas de este principio se encuentran, entre otras: la colaboración, solidaridad, claridad, diligencia, equilibrio, reciprocidad y lealtad, que conducen a vedar el abuso del derecho o el enriquecimiento sin causa y que no admiten discrecionalidad alguna, pues el propio juez en su aplicación está sometido a los preceptos del principio. En el ejemplo desarrollado en este artículo, tres de las reglas derivadas de la buena fe objetiva aplicables al caso son: lealtad, diligencia y prohibición de ir en contra de los actos propios.

En cuanto a la lealtad, para Bianca (p. 479, 1998, citado por Ordoqui, 2012c), se derivan a su vez los siguientes deberes: a) Se deben realizar las conductas necesarias para colaborar activamente con la tutela de los intereses de la otra parte. Es decir, ello lleva implícito un deber de solidaridad o colaboración. Cada una de las partes asume el deber de salvaguardar la utilidad de la otra en los límites en que ello no comprometa un sacrificio apreciable. b) Se debe comunicar todo lo que sea relevante para la ejecución del contrato. c) Además, el deber de lealtad como proyección de la buena fe en la conducta debida por las partes, lleva a tres comportamientos: no suscitar intencionalmente la falsa confianza; no especular con la falsa confianza; y no desconocer la confianza que razonablemente se ha generado en la otra parte. En consecuencia, bajo este deber se puede amparar el derecho de información que tienen los contratantes.

\section{Deber de información de las partes}

El deber de información es una de las reglas derivadas del principio de la buena fe contractual que más toma relevancia en el ejemplo propuesto en este escrito, al ser el punto base del pleito entre los contratantes. El contratante cedente prefiere guardar silencio acerca del estado actual del contrato objeto de la cesión, mientras que el cesionario adopta una conducta indiferente y desinteresada en cuanto a la exigencia de la información del negocio jurídico cedido.

No es discutible que pueden existir entre las partes deberes de conducta, no estipulados expresamente, que en ocasiones constituyen genuinas prestaciones de carácter accesorio. Así, según lo expresado por Díez (2012), puede haber en este sentido, especiales deberes de información entre las partes, que no solo se refieren a una información precontractual, sino a una información sobre la marcha de los asuntos. Se trata de deberes implícitos que acompañan a todo derecho contemplado en un acto especial de ejercicio.

Frente a ambas posturas, se debe hacer una valoración sobre el alcance de este deber, pues de un lado, la omisión a brindar o suministrar toda la información concerniente al negocio jurídico que se está celebrando, se traduce en una falta a la regla derivada de la buena fe, esto es deber de informar al co-contratante. Por el otro lado, la actitud despreocupada y negligente en el recaudo o recolección de la información, trascendental en este caso del contrato en cuestión, también resulta ser una falta al deber de información, como quiera que el beneficiario fuera el mismo contratante, es decir el deber de informarse a sí mismo. 
El deber de informar supone no solo conductas negativas, en el sentido de no mentir, sino conductas positivas, en sentido de dar lo que hace falta, aunque no se le pida, en lo que refiere a información y asesoramiento para lograr que el consentimiento sea informado. Para Ordoqui (2012c), no solo se excluye o prohíbe el actuar con falsedad o deshonestidad, sino que se impone el deber positivo de decir la verdad aun cuando no se le pida la información, de manera que, si con la información recibida no queda lo suficientemente clara, investigue, pregunte y busque identificar los factores y elementos que, con los recibidos, le permitan alcanzar la suficiencia de la información.

El deber de información consiste en dar noticia, informar, hacer saber a la contraparte de las circunstancias, cualidades y situaciones de hecho sobre el objeto del contrato, el contenido y los efectos de este, entre otros elementos, que permiten dentro del periodo precontractual, la determinación de la decisión de contratar en las condiciones que permitan satisfacer los propios intereses de los contratantes, como también la subsiguiente ejecución del contrato orientado al cumplimiento debido de las obligaciones a cargo, bajo los postulados de buena fe (Chinchilla, 2011, párr. 6)

Para Rengifo (2011) el deber de información en la etapa precontractual, adquiere relevancia en cuanto el contenido de este se acota a lo que sea relevante y suficiente, con miras a la toma de una decisión. La importancia de la cuestión radica cuando, la falta de información determinó el consentimiento, entendiéndose ello en el sentido que, lo que no ha sido revelado ejerció una influencia tal sobre el co-contratante que, de haber conocido la información que no le fue comunicada (reticencia) o falseada, no hubiera concluido el contrato, o lo habría hecho bajo otras condiciones, más favorables.

Sin embargo, Rengifo (2011) hace referencia a situaciones de asimetría contractual, en la cual una de las partes tiene mayor poder de negociación sobre la otra, traducido además en la información base de la negociación, circunstancia que en el ejemplo no se presenta, pues como se indica se trata de dos comerciantes experimentados en igualdad de condiciones. El autor expone el deber de información en situación de asimetría, así:
Por ello se hubo de afirmar atrás que el cumplimiento del deber de informar y la carga de informarse se debe apreciar de acuerdo con la naturaleza del contrato $y$, por supuesto, la calidad de las partes. Una cosa es el calibre del deber de informarse en el negocio pensado con el familiar o el amigo y otro será cuando se contrata con el extraño o el competidor (párr. 19).

Sin embargo, no por esa asimetría se debe desconocer el deber de diligencia que recae en quien desea celebrar un contrato, porque solo estando imposibilitado para acceder a la información es que se impide el conocimiento a la información requerida.

Obsérvese que ese deber de información es a favor de quien está en imposibilidad de informarse por sí mismo o de quien confía en el otro sujeto contractual, es decir, que la existencia del deber no excluye de parte del otro sujeto la carga de cuidado y sagacidad que se debe tener en los negocios que le incumben (párr. 19).

En el mismo sentido se habla del deber de informarse o auto información, en virtud del cual:

[...] la diligencia exigida al acreedor de la información el deber de tomar iniciativas oportunas dirigidas a conseguir la información necesaria y determinante que le permita [...] fortalecer el propio consentimiento para determinar la conveniencia de celebrar el contrato y ejecutarlo conforme a los cánones de la buena fe. [...] De ahí que el acreedor de la información no deberá adoptar un comportamiento pasivo $\mathrm{y}$, por el contrario, deberá buscar diligentemente la información que de acuerdo con su posición deba conocer, en aras de una adecuada colaboración en el cumplimiento de las obligaciones emanadas de la relación negocial (Chinchilla, 2011, p. 341).

En consecuencia, el deber de información no recae únicamente en quien posea la información, sino que también le corresponde a la contraparte ignorante, como un desarrollo de su diligencia, visto a través del despliegue de actos positivos y concretos para salir de un estado de ignorancia, pues se insiste, es un negocio que redundará a su favor. 
Esta diligencia que debe observar el cocontratante es denominada también como el deber o carga de corrección, que

no solamente significa abstenerse de vulnerar la legalidad y la moralidad fundamentales, u omitir celadas al destinatario de la declaración o al público en general, sino que implica un evidente celo en la observancia de toda la diligencia que las reglas comerciales, de cortesía y de lealtad prescriben, hasta llegar al deber de solidaridad (colaboración) (Hinestrosa, 2015, p. 384).

Esta carga de corrección de los contratantes, particularmente frente al derecho de información implica entonces una actitud enérgica que se refleje en la investigación y obtención de la información y así pueda demostrarse.

\section{Para Hinestrosa (2015):}

el deber de información, fuera de no ser absoluto, aun cuando sí general, ha de compaginarse con las cargas de advertencia y providencia que pesan sobre toda persona que va a disponer de sus intereses, tanto mayor cuanto más importante, o arriesgada, sea la operación: "carga de auto-información". Lo que conduce a un cotejo y hasta un equilibrio entre el deber de informar y el deber de informarse, acudiendo a la otra parte, como también a terceros, que podía llegar, dado el caso de omisiones mutuas, a una "compensación de culpas", y a una verificación circunstanciada de la información debida, la provista y la podida acopiar (p. 704).

Este deber de auto informarse está implícito en la máxima legal que establece que la ignorancia de la ley no sirve de excusa. Esta ignorancia no está protegida por el ordenamiento jurídico, por el contrario, tanto la ley como la jurisprudencia han sido enfáticos en señalar que no le es posible a un ciudadano excusarse en la ignorancia de la ley para incumplirla. Es más, en la sentencia C-651 de 1997 la Corte Constitucional expresamente estableció que:

Es necesario exigir de cada uno de los miembros de la comunidad que se comporte como si conociera las leyes que tienen que ver con su conducta. [...] La obediencia al derecho no puede dejarse a merced de la voluntad de cada uno, pues si así ocurriera, al mínimo de orden que es presupuesto de la convivencia comunitaria, se sustituiría la anarquía que la imposibilita (Párr. 1).

Además, señala.

[...] c, relevantes en el problema que se analiza, se reducen a dos categorías: 1) las que imponen deberes; y 2) las que indican modos de proceder adecuados para lograr ciertos fines (Párr. 17).

Sobre estas dos categorías la Corte hace un estudio para concluir que las consecuencias de ignorar tanto los deberes como los modos de proceder las asume la parte que decide ignorarlos u omitirlos. Así, la Corte indica que:

[...] los deberes esenciales que a una persona ligan como miembro integrante de una comunidad pueden captarse de manera espontánea mediante la interacción social. Como reglas típicas de la segunda categoría, pueden citarse las que establecen la manera de celebrar contratos. La inobservancia de tales reglas no apareja propiamente sanciones sino más bien resultados fallidos (Párr. 32).

En el caso bajo estudio, el cesionario que ignora todas las circunstancias que rodean el contrato objeto de cesión está llamado a exigir todo lo relacionado con este, bien a través de sus propios medios, tales como investigaciones dentro de su propio ámbito, como a través de su contraparte mediante peticiones formales o informales que den cuenta de cualquier circunstancia que le permita tomar una decisión coherente con los fines pretendidos. De otra manera, su voluntad estaría basada únicamente en el ánimo, voluntad de obtener provecho con la celebración de un negocio jurídico (buena fe subjetiva como un estado de conciencia), más no en actos de búsqueda, recolección o recaudo de información desplegados y constatables que le indique eso (buena fe objetiva).

En el ejemplo bajo estudio nace el interrogante respecto de la diligencia en cabeza del cesionario "C" del contrato de distribución, en el cumplimiento del deber de auto informarse como quiera que este, en afán de obtener un negocio lucrativo omitiera requerir información sobre el estado del contrato, así, se cuestiona si la conducta negligente del cesionario " $\mathrm{C}$ " merece la protección 
del ordenamiento jurídico. La respuesta ha de ser negativa, por lo siguiente: el deudor no es un actor pasivo en la relación jurídica negocial, tiene que participar activamente con el acreedor, no solo porque así lo dictan las reglas de la buena fe objetiva, sino porque de su participación depende la satisfacción y cumplimiento de los propósitos del contrato celebrado. En palabras de Ospina Fernández y Ospina Acosta (2005):

[...] los actos jurídicos y las obligaciones, en general, deben ser cumplidos de buena fe, es decir, lealmente, con la intención positiva de realizar la finalidad social y jurídica a que obedecen. Más esto no es suficiente. A las buenas intenciones hay que agregar algo más: prudencia, diligencia, cuidado en la ejecución de lo debido, pues dicha finalidad no solo puede frustrarse porque el deudor abrigue el ánimo dañado de incumplir, sino también porque culposamente deje de poner los medios adecuados, bien sea por torpeza, bien por negligencia o descuido ( p. 325)

\section{Prohibición de alegar la propia torpeza}

Otra de las reglas dimanada de la buena fe es la prohibición de alegar la propia torpeza, regla que en el contexto de este escrito se estudia de cara al comportamiento del contratante cesionario, y que se encuentra como principio en el ordenamiento jurídico colombiano, según la Corte Constitucional al manifestar que es claro que su formulación explícita no se halla en ningún artículo del ordenamiento colombiano, pero que sí está dentro del sistema, pues

[...] no hay duda de que quien alega su propia culpa para derivar de ella algún beneficio, falta a la buena fe, entendida como la ausencia de dolo, la conciencia de que el comportamiento que se observa es conforme al derecho, y los fines que persigue están amparados por éste (Sentencia C-083, 1995, párr. 5).

Para Neme (2010), vinculada a esta prohibición, está la de ir en contra de los actos propios, regla denominada en latín venire contra factum proprium que encuentra sustento en la concepción romana, según la cual es costumbre observar y legítimo esperar en las relaciones entre hombres de honor que se honre la confianza en el cumplimiento de las expectativas recíprocas.
Así, si el cesionario por cuenta propia decide recibir un contrato de distribución, sin cuestionar el estado de este ni ahondar en las afirmaciones de su contraparte, para obtener provecho económico o una rentabilidad, no puede justificar su conducta, a efectos de evitar una responsabilidad civil por incumplimiento del contrato de distribución, en su propia torpeza, es decir, en su negligencia en la etapa precontractual y haber celebrado un contrato de cesión a ciegas.

De esta forma, el cesionario no solo está defraudando la confianza legítima creada en el contratante cedente, sino además en el contratante cedido, quien estuvo al margen de la cesión.

Frente a la conducta del cedente y la del cesionario, ¿cuál merece mayor reproche?

El cedente no cumple el deber de informar al cesionario, que el contrato de distribución está en estado de incumplimiento, conducta reticente, que podría ser catalogada como de mala fe, pues tiene en su poder esa información y, con previo conocimiento de la utilidad que le puede reportar al cesionario, decide callar.

El cesionario prefiere atenerse a lo dicho por el cedente y celebra el contrato buscando un provecho económico a largo plazo, conducta negligente que, también, puede tomarse como falta a la buena fe objetiva, como quiera que está en capacidad de exigir toda la información relacionada con el contrato en cuestión, y aun así no lo hace.

Si ambas partes incumplieron el principio de la buena fe, ¿cuál conducta merece mayor reproche? Para Ordoqui (2012b) si se actúa con dolo o culpa no se puede invocar la buena fe, pues no puede existir cuando se está actuando negligentemente y esa transgresión, inevitablemente, ha de sancionarse, y la sanción específica que en este caso corresponde; no puede ser otra que impedir al culpable invocar la buena fe. Para Hinestrosa 2015):

[...] es natural concluir que la falta de provisión de la información debida, oportuna, pertinente, veraz, completa, ha de generar consecuencias adversas para quien calló, en la medida en que esa omisión haya significado a la otra parte la celebración de un contrato que no habría celebrado de haber contado con 
aquella noticia, o haberlo celebrado en otras condiciones [...] (p. 711).

La postura de la Corte Suprema de Justicia y del Tribunal de Arbitramento del Centro de Conciliación y Arbitraje de la Cámara de Comercio de Bogotá es similar y en algunos fallos enfatiza en los deberes derivados de la buena fe objetiva, concluyendo que la actuación del contratante debe ceñirse a ese tipo de buena fe y que la creencia o convicción no son suficientes para alegar una protección jurídica:

En 1936 la Corte Suprema de Justicia señaló que la buena fe requerida en el tercero debe reunir máximum de cualidades: debe estar exenta de toda culpa; es decir, que no basta que el tercero que la invoca haya tenido la creencia o la convicción de estar negociando [...], sino que es menester que esa creencia no sea el resultado de una imprudencia o de una negligencia en que no habría incurrido una persona avisada y diligente. [...] sobre esa especie de buena fe que no sólo implica la ausencia del elemento "malicia" sino que implica también, por parte de quien la alega, la prueba de diligencia y prudencia (Sala de Casación Civil, ID: 419742, 1936).

En el año 2001 el alto Tribunal recalcó que para que la ignorancia o estado de desconocimiento sea legítimo es necesario demostrar la diligencia, de lo contrario será inexcusable ( Expediente 6146,2001 )

Posteriormente, en 2011, reafirmó que los efectos de la cesión se traducen en que el cesionario recibe el contrato en el estado en que se encuentra, sin modificación alguna y, así mismo asume las consecuencias negativas de los incumplimientos proyectados (11001-3103-0322001-00847-01, 2011).

En igual sentido falló el Tribunal de Arbitramento del Centro de Conciliación y Arbitraje de la Cámara de Comercio de Bogotá en laudos proferidos los años 2007 y 2011 manifestando en el primero que el deber de información no se encuentra desligado del deber de diligencia a cargo de la parte que lo reclama, más aún cuando es un profesional en los negocios, pues por su posición éste conocía o debía conocer los hechos omitidos por la contraparte. Así, la parte que conozca circunstancias determinantes para su co-contratante debe informárselas, pero, ese co-contratante debe estar en imposibilidad objetiva y subjetiva de conocerlas por sí mismo, pues esas especiales circunstancias hacen parte del fundamento para otorgar el consentimiento o influir en éste para celebrar o no un contrato o a hacerlo, pero en condiciones distintas, de lo contrario estaría actuando con menor diligencia de la debida (Cámara de Comercio de Bogotá, 2007)

Para el año 2011, el Tribunal de Arbitramento del Centro de Conciliación y Arbitraje de la Cámara de Comercio de Bogotá argumentó que:

Observa el Tribunal que no es de recibo alegar la propia culpa como causal de inexistencia de un contrato. De acuerdo con el artículo 863 del Código de Comercio las partes deben proceder de buena fe exenta de culpa en el periodo precontractual, y si PÁEZ LANCHEROS [...] no conocieron el texto de los contratos que les iban a ceder y sin embargo firmaron el acuerdo conciliatorio, no observaron la diligencia a que estaban obligados. [...] Por lo demás, no sobra recordar que PÁEZ LANCHEROS tenía experiencia en materia de cesión de contratos.

\section{CONCLUSIONES}

El contrato de cesión, regulado de manera general por el Código de Comercio, establece una serie de reglas que pueden ser modificadas por las partes, cedente y cesionario. En este negocio jurídico, se cede la posición contractual del cedente respecto de un contrato previo a un tercero denominado cesionario, quien entra a ejecutar ese contrato conforme las disposiciones contractuales pactadas y a las normas legales que por su naturaleza correspondan.

En todo el iter contractual estos contratantes están obligados a observar, no solo las normas positivas, sino todas aquellas que integran el ordenamiento jurídico, siendo el principio de la buena fe uno de los pilares del sistema jurídico actual.

No obstante, la buena fe que se protege jurídicamente en el ámbito contractual es la llamada: buena fe objetiva, que implica el despliegue de ciertas conductas por parte de los actores, de actos que serán evaluados posteriormente $\mathrm{y}$, no la buena fe subjetiva, 
que implica únicamente una creencia de estar actuando conforme a derecho.

Del estudio realizado y respecto del ejemplo propuesto en la introducción, toman especial relevancia los deberes dimanados de la buena fe objetiva que se radican en cabeza de las partes "B" cedente y " $\mathrm{C}$ " cesionario. El más importante en este caso es el deber de información, en virtud del cual, el contratante "B" que posea los conocimientos relativos al negocio que se celebra estará obligado a compartirlos a su co-contratante, a fin de que nazca el negocio jurídico libre de reservas o engaños. Pero también radica en cabeza de "C", el co-contratante ignorante, el deber de auto informarse, de asesorarse y esto es, actuar con diligencia en la obtención de información que pueda serle de utilidad para tomar la decisión que mejor convenga a sus intereses.

El problema gira alrededor del alcance del deber de información del cedente y cesionario, respecto del estado de incumplimiento de un contrato de distribución, información no entregada y no exigida que da lugar a un evento de responsabilidad.

En el ejemplo dado se reprocha la conducta tanto del cedente como del cesionario, pues ambos incumplen su deber correlativo de informar e informarse acerca del contrato objeto de la cesión, pero, en un primer momento se podría pensar o concluir que merece mayor reproche el cedente, en tanto obstaculiza al cesionario a tomar una decisión informada y consciente de si recibir o no un contrato de distribución incumplido y se lucra con una cesión que lo deja libre de responsabilidad, en principio.

Se entiende esta postura por cuanto parece más palpable el quebrantamiento de la buena fe por parte del cedente, no así del cesionario, quien por las actuaciones u omisiones de su cocontratante y su negligencia recibiera a ciegas el contrato de distribución.

Sin embargo, los siguientes aspectos logran cambiar radicalmente dicha postura para ahora inclinarse a apuntar al cesionario, cuya conducta merecería un mayor reproche:

En primer lugar, se debe hacer un estudio global del caso, analizando las capacidades de cada una de las partes y observando que se está ante una relación simétrica entre comerciantes expertos en este tipo de negocios, esto es, en igualdad de condiciones. Es decir, no hay un poder de sometimiento de uno de los contratantes, ni de obediencia que pueda disculpar la conducta negligente.

Además, no se puede perder de vista que se trata de un contrato comercial, bilateral y oneroso, lo que significa que el negocio jurídico redunda o reporta utilidad en favor de ambas partes, pero adicionalmente, que los contratantes tienen a su cargo diversas obligaciones, entre ellas la de actuar diligentemente, y en el caso puntual del cesionario, la de informarse suficientemente para asegurar su propio consentimiento.

En segundo lugar, como se menciona, los contratantes están obligados no solo a lo que expresamente disponen en el contrato, sino a todo aquello relativo al negocio jurídico y en especial a actuar según el principio de la buena fe objetiva, por lo que el cesionario tiene el deber de exigir la información que dé cuenta de todos los asuntos relacionados con el contrato de distribución, siendo uno de los más evidentes, el estado de cumplimiento de éste.

En tercer lugar, el estado de ignorancia del cesionario es superable, pues con el recaudo mínimo de la información basta para salir de su estado de ignorancia, entonces con el requerimiento formal o informal al cedente de la información es suficiente para demostrar que su comportamiento se ajusta al principio de la buena fe objetiva.

En cuarto lugar, el ordenamiento jurídico no protege la negligencia, menos aún a quien pretenda alegar la propia torpeza para obtener provecho de ello y en el contexto presentado, el cesionario al querer obtener la utilidad deseada del contrato de distribución y evitar pérdidas, busca disculpar su propia negligencia argumentando la falta de su co-contratante a la buena fe por cuanto no le brindó la información sobre el estado de cumplimiento, pero a la vez deja en evidencia su propia falta al no auto informarse de forma previa y suficiente.

En quinto lugar, la buena fe objetiva obliga a los contratantes a desplegar conductas tendientes a lograr el negocio jurídico previsto y en el caso del cesionario la actuación debe corresponder al 
deber de auto informarse a fin de que el contrato de distribución le resultara útil y beneficioso.

Finalmente, no puede tomarse a la buena fe subjetiva como una excepción al deber de diligencia del cesionario, no solo porque no se encuentra consagrada como tal en el ordenamiento jurídico, ni expresa ni tácitamente -según se vio en la máxima la ignorancia de la ley no sirve de excusa-, sino porque además ello resulta ser una disculpa a la negligencia de los contratantes frente a sus propios deberes, beneficiando, entonces, la actitud pasiva y el estado de ignorancia buscado voluntariamente.

\section{BIBLIOGRAFÍA}

- Arrubla P., J. A. (2008). Contratos mercantiles. Tomo I. Teoría del Negocio Mercantil. Medellín: Biblioteca Jurídica Diké.

- Cámara de Comercio de Bogotá. Centro de Arbitraje y Conciliación. Laudo arbitral Biocombustibles S.A. vs. Jorge Enrique Paéz Lancheros y Fanny Lancheros de Páez. Árbitros Jorge Arango Mejía, Gabriel Jaime Arango Restrepo, Andrew Abela Maldonado (29 de noviembre de 2011).

- Cámara de Comercio de Bogotá. Centro de Arbitraje y Conciliación. Laudo arbitral Tv Cable S.A. y otras contra Empresas Públicas de Medellín ESP y otras. Árbitros Álvaro Mendoza Ramírez, Carmenza Mejía Martínez, Carlos Gustavo Arrieta Padilla (27 de noviembre de 2007).

- Chinchilla I., C. A. (2011). El deber de información contractual y sus límites. Dsiponible en https://revistas.uexternado. edu.co/index.php/derpri/article/ view/2992/2636

- Código de Comercio, [C.Co.]. Decreto 410 de 1971. Artículo 887 y ss. 27 de marzo de 1971 Bogotá.

- Corte Constitucional. (1 de marzo de 1995). Sentencia C-083, No. Expediente D-665. [MP Carlos Gaviria Díaz].

- Corte Constitucional. (3 de diciembre de 1997). Sentencia C-651, No. Expediente D-1698. [MP Carlos Gaviria Díaz].

- Corte Suprema de Justicia, Sala de Casación Civil. (20 de mayo de 1936) Expediente No 419742. [MP Eduardo Zuleta Ángel]. Gaceta
Judicial, Tomo XLIII No. 1904, pp. 44 - 60.

- Corte Suprema de Justicia, Sala de Casación Civil. (4 de abril de 2001). Expediente No. 5628. [MP José Fernando Ramírez Gómez].

- Corte Suprema de Justicia, Sala de Casación Civil. (2 de agosto de 2001). Expediente No. 6146. [MP Carlos Ignacio Jaramillo Jaramillo].

- Corte Suprema de Justicia, Sala de Casación Civil. (19 de octubre de 2011) Expediente No. 11001-3103-032-2001-00847-01. [MP William Namén Vargas].

- Díez P., L. (2012). Fundamentos del Derecho Civil Patrimonial. Vol. I. Madrid: Editorial Aranzadi.

- DíezP., L., \& Guillón,A. (1987). “Introducción. Derecho de la persona. Autonomía privada. Persona jurídica". In Sistema de Derecho Civil. Vol. I. Madrid: Editorial Tecnos, pp. 327, 338.

- Hinestrosa, F. (2015). Tratado de las obligaciones II. De la fuente de las obligaciones. Negocio jurídico.Vol.II. Bogotá: Universidad Externado de Colombia.

- Hinestrosa, F. (2002). Tratado de las obligaciones. Concepto, Estructura, Vicisitudes. Tomo I. Bogotá: Universidad Externado de Colombia.

- Hinestrosa, F. (2000). "De los principios generales del Derecho a los principios generales del contrato". Revista de Derecho Privado, 5, pp. 3-22. Disponible en https://contratosmercantilesosmarose. files.wordpress.com/2010/03/de-losprincipios-del-derecho-a-los-principios- 
del-contrato.pdf

- Jaramillo, C. I. (2017) Derecho privado. Estudios y escritos de derecho patrimonial. Tomo III. Derecho de contratos. Vol. 2. Parte General (continuación). Parte Especial. Bogotá: G. E. Ibañez y Pontificia Universidad Javeriana.

- Mantilla E., F., Molina B., C. M., Molina S., C., Ternera B., F., Aljure S., A., Anzola G., M., \& Bargue, N. (2007). Los contratos en el derecho privado. Bogotá: Editorial Universidad del Rosario, Legis.

- Muñoz, L. (1960). Derecho Comercial. Contratos. Buenos Aires: Tipográfica Editora Argentina

- Neme Villarreal, M. L. (2010). La buena fe en el derecho romano. Extensión del deber de actuar conforme a buena fe en materia contractual. Bogotá: Universidad Externado de Colombia.

- Neme Villareal, M. L. (2009). Buena fe subjetiva y buena fe objetiva. Equívocos a los que conduce la falta de claridad en la distinción de tales conceptos. Revista de Derecho Privado, 17, 45-76

- Neme Villarreal, M. L. (2006). El principio de buena fe en materia contractual en el sistema jurídico colombiano. Revista de Derecho Privado, 11, 79-126.

- Ordoqui Ca., G. (2012a). "Buena fe contractual”. En G. E. Ibañez (Edits.), Buena fe contractual. Vol. Colección Internacional No. 35, pp. 122. Bogotá: Pontificia Universidad Javeriana.

- Ordoqui C., G. (2012b). "Buena fe contractual”. En G. E. Ibañez (Edits), Buena Fe Contractual. Vol. Colección Internacional No. 35, pp. 240-242). Bogotá: Pontifica Universidad Javeriana.

- Ordoqui C., G. (2012c). "Buena fe contractual”. En G. E. Ibañez (Edits), Buena Fe Contractual. Vol. Colección Internacional No. 35, pp. 377, 378. Bogotá: Pontificia Universidad Javeriana.

- Ospina F., G., \& Ospina A., E. (2005). Teoría General del Contrato y del Negocio Jurídico. Bogotá: Editorial Temis.

- Rengifo, E. (2011) El deber precontractual de información. Disponible en http:// rengifo.esmarthosting.co/publications / el-deber-precontractual-de-informacion/ 